\title{
STRATEGI PENGEMBANGAN PENDIDIKAN AGAMA ISLAM PADA ANAK USIA DINI DI TK TAAM ADINDA MENGANTI GRESIK
}

\author{
Muhammad Syaikhon, SHI., MHI.; Jauharotur Rihlah, S.Pd., M.Pd \\ PGPAUD, FKIP, Universitas Nahdlatul Ulama Surabaya \\ Kampus A : Jl. SMEA no. 57 Surabaya Kampus B : Jl. Jemursari No. 51 - 57 \\ Surabaya (RSI. Jemursari) \\ muhammadsay87@unusa.ac.id
}

\begin{abstract}
Abstrak
Penelitian ini adalah jenis penelitian lapangan dengan pendekatan deskriptif kualitatif dengan judul Strategi Pengembangan Pendidikan Agama Islam Pada Anak Usia Dini di TK TAAM Adinda Menganti Gresik yang bertujuan untuk mendeskripsikan (1) bagaimana strategi pengembangan PAI di TK TAAM Adinda Kepatihan Menganti Gresik? (2) apa saja faktor pendukung dan penghambat dalam proses penerapan strategi pengembangan PAI di TK TAAM Adinda Kepatihan Menganti Gresik? (3) bagaimana hasil dari penerapan strategi pengembangan PAI terhadap prestasi belajar peserta didik di TK TAAM Adinda Kepatihan Menganti Gresik?.

Berdasarkan fokus masalah di atas, maka tujuan penelitian ini adalah: (1) untuk mengetahui bagaimana strategi pengembangan PAI di TK TAAM Adinda Kepatihan Menganti Gresik? (2) untuk mengetahui faktor pendukung dan penghambat dalam proses penerapan strategi pengembangan PAI di TK TAAM Adinda Kepatihan Menganti Gresik? (3) untuk mengetahui bagaimana hasil dari penerapan strategi pengembangan PAI terhadap prestasi belajar peserta didik di TK TAAM Adinda Kepatihan Menganti Gresik?.

Temuan penelitian ini dapat disimpulkan, bahwa: strategi pengembangan PAI yang dilakukan di TK TAAM Adinda Kepatihan Menganti Gresik sangat tepat sekali, dengan mengadopsi dari teori-teori dan konsep pembelajaran ala Rasulullah dan dipadukan dengan konsep dan teori-teori pembelajaran yang berkembang saat ini. Faktor pendukung penerapan strategi ini adalah pendidik memiliki kemampuan menyampaikan ajaran agama Islam, adanya fasilitas yang berupa TV dan VCD, dan memiliki buku-buku Islami sebagai penunjang pembelajaran. Sedangkan faktor penghambatnya adalah kurangnya persediaan sarana dan prasarana yang menunjang proses pembelajaran, terbatasnya media pembelajaran sehingga metode yang digunakan dalam pembelajaran pun kurang bervariasi, dan perbedaan latar belakang keluarga serta minimnya dalam pemahaman agama. Keberhasilan pembelajaran PAI tersebut telah berpengaruh positif bagi TK TAAM Adinda baik secara sosiologis maupun psikologis.
\end{abstract}

Kata Kunci: Strategi Pengembangan ; Pendidikan Agama Islam ; Anak Usia Dini.

Strategi Pengembangan Pendidikan Agama Islam 


\begin{abstract}
This research is a kind of field research with qualitative descriptive approach with title Islamic education development strategy in early childhood in kindergarten TAAM Adinda Menganti Gresik aimed at described (1) how PAI development strategy in kindergarten TAAM Adinda Kepatihan Menganti Gresik?, (2) what supporting and inhibiting factors in the process of applying PAI development strategy in kindergarten TAAM Adinda Kepatihan Menganti Gresik? (3) how the result of the implementation of PAI development strategy to students learning achievements in kindergarten TAAM Adinda Kepatihan Menganti Gresik?.

Based on the focus, so the purposes of this research are: (1) to know how PAI development strategy in kindergarten TAAM Adinda Kepatihan Menganti Gresik? (2) to know the supporting and inhibiting factors in the process of applying PAI development strategy in kindergarten TAAM Adinda Kepatihan Menganti Gresik? (3) to see how the results of the application of PAI development strategy to students learning achievements in kindergarten TAAM Adinda Kepatihan Menganti Gresik.

The findings of this research can be concluded that: PAI development strategy made in kindergarten TAAM Adinda Kepatihan Menganti Gresik very exactly, by adopting the concept of the theories and learning from the messenger and integrated with the concept and theories learning that developing now. The supporting factors in the implementation of this strategy is the educator has the ability to teach Islamic teachings, the existence of facilities in the form of TV and VCD, and have Islamic books as supporting learning. While the inhibiting factors are lack of supplies of facilities and infrastructure that support the learning process, limited learning media so that the methods used in learning are also less varied, and differences in family background and lack of understanding of religion. The success of PAI learning has positively influenced for TK TAAM Adinda both sociologically and psychologically.
\end{abstract}

Keywords: Development Strategy; Islamic Education ; Early childhood.

\title{
Pendahuluan
}

Penyelenggaraan PAI di lembaga PAUD masih menunjukkan berbagai permasalahan yang kurang menyenangkan. Seperti halnya proses pembelajaran PAI hingga saat ini masih sebatas sebagai proses penyampaian "pengetahuan tentang Agama Islam" dan kurang mampu mengubahnya menjadi "makna" dan "nilai". PAI lebih menekankan pada aspek knowing dan doing dan belum mengarah pada aspek being. Kegagalan penyelenggaraan PAI selama ini disebabkan karena praktek penyelenggaraan pendidikan hanya memperhatikan aspek kognitif semata dan mengabaikan pembinaan aspek afektif. Untuk dapat mengatasi dan menyelesaikan 
problem-problem tersebut dibutuhkan strategi tertentu dalam pengembangan PAI. Strategi menunjuk pada sebuah perencanaan untuk mencapai sesuatu, sedang metode adalah cara yang dapat digunakan untuk melaksanakan strategi.

TK Taman Asuh Anak Muslim (TAAM) Adinda merupakan salah satu lembaga pendidikan anak usia dini yang berada di desa Kepatihan kecamatan Menganti kabupaten Gresik. Pendidikan agama Islam di lembaga ini menjadi sebuah prioritas utama dalam pembelajaran. Materi agama yang diajarkan tidak hanya sekedar berbentuk teori semata, akan tetapi juga diajarkan secara praktis agar nilainilai Islam tertanam pada peserta didik .

TK Taman Asuh Anak Muslim (TAAM) Adinda adalah salah satu sekolah pendidikan untuk anak usia dini dimana di dalamnya terdiri dari beberapa pengajar yang tidak hanya bertugas memberikan pengajaran kepada anak-anak, namun juga memberikan asuhan atau penjagaan kepada anak-anak tersebut mewakili peran orang tua. TK TAAM Adinda mengajarkan kepada peserta didiknya muatan membaca AlQur'an dimulai dari membaca secara tartil sampai dengan penggunaan metode tertentu untuk mengaji dengan seni. Selain itu, peserta didik juga diajarkan tentang do'a-do'a harian, hadis-hadis pilihan, sholat berjama'ah, asmaul husna, ziarah dan lain-lain.

Dengan latar belakang masalah yang telah diuraikan di atas, maka penulis merasa tertarik untuk melakukan penelitian lebih mendalam tentang bagaimana strategi pengembangan pendidikan agama Islam pada anak usia dini di TK TAAM Adinda Kepatihan Menganti Gresik.

\section{Metode}

Penelitian ini adalah jenis penelitian lapangan dengan pendekatan deskriptif kualitatif. Teknik pengumpulan data dilakukan dengan cara observasi, wawancara mendalam, dan dokumentasi. Analisis data dilakukan dengan tiga tahap, yaitu reduksi data, penyajian data, dan penarikan kesimpulan/verifikasi. 


\section{Hasil Dan Pembahasan \\ 1. Strategi Pengembangan PAI di TK TAAM Adinda Kepatihan Menganti Gresik.}

\section{a. Tujuan Pengembangan PAI}

Secara umum tujuan pengembangan PAI di TK TAAM Adinda adalah untuk mengembangkan kemampuan peserta didik agar dapat memahami, menghayati dan mengamalkan nilai-nilai ajaran agama Islam sesuai dengan kebutuhannya. Sedangkan secara khusus adalah untuk menyemai peserta didik agar menjadi manusia yang beriman dan bertaqwa kepada Allah swt, cerdas, terampil, serta mandiri dengan mengenalkan nilai-nilai ajaran Islam semenjak usia dini.

Dengan mengenalkan nilai-nilai ajaran Islam semenjak usia dini, maka peserta didik akan memiliki akidah yang kuat dan pemahaman tentang ajaran Islam yang lebih baik serta mampu melaksanakan ajaran Islam tersebut dalam kehidupan sehari-hari.

\section{b. Pendekatan dalam Pembelajaran PAI}

Pembelajaran yang dilakukan di TK TAAM Adinda menggunakan pendekatan yang berpusat pada peserta didik (student centred approaches). Adapun dalam pelaksanaannya, pendekatan yang digunakan adalah pendekatan belajar aktif (active learning approaches) dan pendekatan belajar yang menyenangkan (happy learning approaches). Melalui dua pendekatan ini, sistem pembelajaran yang digunakan ada empat sistem yaitu : 1) belajar sambil bermain (learning by playing); 2) belajar sambil bekerja (learning by doing); 3) pembelajaran terpadu/terintegrasi (integrated learning) dan 4) situasi pembelajaran yang menyenangkan (happinese situation learning).

Pembelajaran aktif (active learning) adalah pembelajaran melalui cara-cara belajar yang aktif menuju belajar yang mandiri. Belajar mandiri merupakan tujuan akhir dari pembelajaran aktif. ${ }^{1}$ Pembelajaran

${ }^{1}$ Eveline Siregar, dan Nara, Hartini, Teori Belajar dan Pembelajaran, Cet. Ke-1, (Bogor: Ghalia Indonesia, 2010), hal. 106.

Muhammad Syaikhon, SHI., MHI; Jauharotur Rihlah, S.Pd., M.Pd 
menyenangkan (happy learning) adalah pembelajaran yang dilakukan dalam situasi yang menyenangkan. Belajar sambil bermain (Learning by playing) adalah pembelajaran yang dalam pelaksanaannya, pendidik harus mampu menciptakan situasi seperti bermain, karena dunia anak-anak identik dengan dunia bermain, sehingga pembelajaranpun harus dilakukan seperti bermain. Belajar sambil bekerja (Learning by doing) adalah pembelajaran yang dilakukan dalam bentuk tindakan. Sedangkan pembelajaran terpadu/terintegrasi (integrated learning) yaitu pembelajaran dilakukan dengan mengintegrasikan antara materi pelajaran dengan tema-tema tertentu.

\section{c. Metode Pembelajaran PAI}

Proses pendidikan di TK TAAM Adinda mulai jam 07.30 - 11.00 WIB. Penetapan waktu proses belajar mengajar tersebut dengan pertimbangan efisiensi biaya. Disamping itu agar peserta didik tidak terlalu capek, sehingga dapat menerima materi pembelajaran dengan maksimal. Ada beberapa metode yang digunakan dalam pelaksanaan pembelajaran di TK TAAM Adinda khususnya dalam pembelajaran PAI yaitu metode bermain, metode cerita, metode keteladanan, metode pembiasaan, metode demonstrasi, dan metode tanya jawab.

\section{d. Prosedur Pembelajaran PAI}

Prosedur pembelajaran PAI yang dimaksud disini adalah tahapantahapan kegiatan yang dilakukan dalam pembelajaran PAI antara lain perencanaan, pelaksanaan, penilaian/evaluasi dan pencapaian hasil.

1) Perencanaan

Dari hasil observasi dan wawancara yang dilakukan oleh peneliti, maka ditemukan bahwa strategi pengembangan PAI pada anak usia dini di TK TAAM Adinda tidak lepas dari adanya pengembangan silabus, 
Rencana Kegiatan Harian (RKH), Rencana Kegiatan Mingguan (RKM), Program Semester (PROMES), dan Program Tahunan (PROTA).

Dalam hal ini penyusunan kurikulum kegiatan PAUD yang ada di TK TAAM Adinda, aspek/lingkup perkembangan peserta didik seperti nilai moral dan agama sangat dominan. Sebab kegiatan PAUD yang diterapkan di lembaga ini merupakan pengembangan dari visi dan misi yang telah disepakati.

2) Pelaksanaan

a). Kegiatan Pembuka

Kegiatan pembuka dari hasil penelitian yang dilakukan oleh peneliti di TK TAAM Adinda, setiap kali membuka kegiatan umumnya hampir sama seperti TK lainnya. Namun peserta didik yang berada di TK ini sebelum kegiatan pembuka diajak sholat dhuha berjamaah dan membaca asmaul husna. Sedangkan dalam kegiatan pembuka digunakan dengan bernyanyi lagu keagamaan, berdoa, membaca surat-surat pendek, dan hadis-hadis pilihan.

b). Kegiatan Inti

Pada kegiatan inti ini, peserta didik diajarkan materi sesuai dengan jadwal yang telah direncanakan. Kemudian peserta didik disuruh memperhatikan, bertanya, mengumpulkan informasi, mengekspresikan ide dan gagasannya, serta mengkomunikasikannya.

c). Kegiatan Penutup

Setelah kegiatan inti selesai, kegiatan selanjutnya ialah kegiatan penutup. Kegiatan ini merupakan kegiatan yang menutup semua rangkaian kegiatan PAUD. Berdasarkan hasil pengamatan peneliti, sebelum berdoa pendidik mendiskusikan kembali materi yang baru saja diajarkan, bercerita pendek yang mengandung pesanpesan dan menginformasikan kegiatan untuk pertemuan berikutnya. Kemudian pendidik mengatur peserta didik untuk duduk yang rapi dan mengajak doa bersama. Selanjutnya selesai doa anak 
dipersilahkan pulang dengan tertib yaitu dengan cara pendidik memberikan pertanyaan tentang materi yang baru saja diajarkan, tebak-tebakan, nyanyian motivasi dan lain-lain. Setelah itu sembari akan pulang, peserta didik berjabat tangan dan mengucapkan salam pada pendidik.

3) Evaluasi

Evaluasi merupakan salah satu komponen integral yang tidak dapat dipisahkan dari kegiatan pembelajaran. Evaluasi ini bertujuan untuk memperoleh informasi keefektifan proses pembelajaran dan hasil dari kegiatan pembelajaran yang telah disampaikan. ${ }^{2}$

Evaluasi atau penilain yang dilakukan di TK TAAM Adinda adalah dengan menggunakan metode obsevasi, penugasan (project), penampilan (performance), tanya jawab, dan hasil karya (product).

4) Pencapaian Hasil

Keberhasilan pembelajaran PAI di TK TAAM Adinda tersebut ternyata telah berdampak positif baik dalam dimensi sosiologis maupun psikologis. Dalam dimensi sosiologis, keberhasilan pembelajaran PAI di TK TAAM Adinda telah meningkatkan kepercayaan masyarakat yang tinggi terhadap lembaga ini. Secara psikologis, meningkatnya kepercayaan masyarakat tersebut semakin menambah semangat dan kepercayaan pengelola.

\section{Faktor pendukung dan penghambat dalam proses penerapan strategi} pengembangan PAI di TK TAAM Adinda Kepatihan Menganti Gresik.

Dalam kegiatan penerapan strategi pendidikan agama Islam pada anak usia dini di TK TAAM Adinda terdapat faktor pendukung dan penghambatnya. Faktor-faktor tersebut baik secara langsung maupun tidak langsung akan mempengaruhi proses dalam kegiatan penerapan strategi pendidikan agama Islam. Berdasarkan hasil pengamatan dan wawancara yang dilakukan oleh hal. 190

\footnotetext{
${ }^{2}$ Dimyati dan Mudjiono, Belajar dan Pembelajaran, (Jakarta: Rineka Cipta, 2006),
} 
peneliti yang menjadi faktor pendukung kegiatan PAUD diantaranya yaitu pendidik memiliki kemampuan menyampaikan ajaran agama Islam, adanya fasilitas yang berupa TV dan VCD, dan memiliki buku-buku Islami sebagai penunjang pembelajaran.

Sedangkan dari hasil pengamatan dan wawancara yang dilakukan peneliti maka didapatkan faktor-faktor yang menghambat proses pengelolaan kegiatan penerapan strategi pendidika agama Islam, yaitu terbatasnya jumlah pendidik yang menyebabkan kelas kurang kondusif, kurangnya persediaan sarana dan prasarana yang menunjang proses pembelajaran, terbatasnya media pembelajaran sehingga metode yang digunakan dalam pembelajaran pun kurang bervariasi, dan perbedaan latar belakang keluarga serta minimnya dalam pemahaman agama.

\section{Hasil dari penerapan strategi pengembangan PAI terhadap prestasi belajar} peserta didik di TK TAAM Adinda Kepatihan Menganti Gresik.

Berdasarkan hasil penelitian, menunjukkan bahwa pembelajaran PAI di TK TAAM Adinda selama ini telah mencapai hasil yang memuaskan. Hasil pembelajaran PAI yang memuaskan disini dapat dilihat dari perolehan nilai PAI peserta didik yang rata-rata mencapai skor sangat baik dengan nilai Berkembang Sangat Baik (BSB) pada ketiga aspek penilaian yaitu kognitif, afektif dan psikomotorik.

Adapun prestasi yang dicapai peserta didik di TK TAAM Adinda dalam pembelajaran PAI adalah sebagai berikut :

a. Materi akidah: Peserta didik mampu mengenal Allah dan sifat-Nya, mengenal ciptaan Allah, mengenal nama malaikat Allah dan tugasnya, mengenal Nabi dan Rasul Allah, dan mengenal adanya kehidupan akhirat, mengenal rukun iman, dan asmaul husna.

b. Materi ibadah: Peserta didik mampu memahami dan mengerjakan kelima rukun Islam, seperti membaca syahadat, mengerjakan shalat wajib dan sunnah yang dilakukan berjamaah, mengenal arti dan cara berpuasa secara sederhana, mengenal arti dan cara berzakat, mengenal dan memperagakan manasik haji. 
c. Materi akhlak: Peserta didik mampu mengerti dan memahami tentang mengucapkan dan menjawab salam, membaca do'a sebelum dan sesudah melakukan kegiatan, bersikap jujur, cara menghormati orang tua dan guru, keihlsan dan tanggung jawab, cara meminta maaf dan memaafkan, tolongmenolong dan bekerja sama, bersikap mandiri, tata cara berperilaku terhadap binatang dan alam.

d. Materi hafalan: Peserta didik mampu menghafal juz 'amma mulai dari surat at-Tin sampai deng an-Nas, menghafal hadis-hadis pilihan seperti hadis tentang larangan makan dan minum sambil beridiri, anjuran sedekah, dan lain-lain, menghafal asmaul husna, menghafal doa sehari-hari seperti doa akan makan, doa akan belajar, dan lain-lain, serta menghafal bacaan-bacaan shalat.

\section{Simpulan dan Saran}

Berdasarkan hasil penelitian dan pembahasan yang telah penulis lakukan tentang Strategi Pengembangan Pendidikan Agama Islam Pada Anak Usia Dini di TK TAAM Adinda Menganti Gresik, dapat diambil kesimpulan sebagai berikut:

1. Strategi pengembangan PAI yang dilakukan di TK TAAM Adinda sangat tepat sekali, sehingga pembelajaran PAI berjalan dengan baik dan dapat mencapai hasil maksimal dengan indikator kualitas output/lulusan TK TAAM Adinda memiliki penguasaan PAI yang sangat baik dilihat dari aspek pengetahuan (kognitif), sikap (afektif) dan keterampilan (psikomotorik). Strategi yang digunakan dalam pelaksanaan pembelajaran di TK TAAM Adinda tersebut mengadopsi dari konsep dan teori-teori pembelajaran ala Rasulullah dan dipadukan dengan konsep dan teori-teori pembelajaran yang berkembang saat ini.

2. Dalam penerapan strategi pengembangan PAI di TK TAAM Adinda Kepatihan Menganti Gresik bukanlah suatu hal yang mudah. Hal ini tidak terlepas dengan adanya faktor pendukung dan penghambat dalam proses pelaksanaannya. Faktor pendukung tersebut diantaranya adalah pendidik memiliki kemampuan menyampaikan ajaran agama Islam, adanya fasilitas yang berupa TV dan VCD, 
dan memiliki buku-buku Islami sebagai penunjang pembelajaran. Sedangkan dari hasil pengamatan dan wawancara yang dilakukan peneliti maka didapatkan faktor-faktor yang menghambat proses pengelolaan kegiatan penerapan strategi pendidikan agama Islam, yaitu terbatasnya jumlah pendidik yang menyebabkan kelas kurang kondusif, kurangnya persediaan sarana dan prasarana yang menunjang proses pembelajaran, terbatasnya media pembelajaran sehingga metode yang digunakan dalam pembelajaran pun kurang bervariasi, dan perbedaan latar belakang keluarga serta minimnya dalam pemahaman agama.

3. Keberhasilan pembelajaran PAI di TK TAAM Adinda tersebut ternyata telah berdampak positif baik dalam dimensi sosiologis maupun psikologis. Dalam dimensi sosiologis, keberhasilan pembelajaran PAI di TK TAAM Adinda telah meningkatkan kepercayaan masyarakat yang tinggi terhadap lembaga ini. Secara psikologis, meningkatnya kepercayaan masyarakat tersebut semakin menambah semangat dan kepercayaan pengelola.

\section{Saran}

Setelah mengadakan penelitian di TK TAAM Adinda Kepatihan Menganti Gresik, maka ada beberapa saran mengenai kegiatan penerapan strategi pengembangan PAI pada anak usia dini, antara lain sebagai berikut :

1. Bagi Kepala Sekolah TK TAAM Adinda Kepatihan Menganti Gresik

a. Perlu adanya peningkatan serta perawatan sarana dan prasarana sebagai penunjang kegiatan penerapan strategi pengembangan PAI pada anak usia dini.

b. Perlu adanya pengembangan kompetensi bagi pendidik dan tenaga kependidikan sebagai peningkatan mutu pendidikan.

2. Bagi Pendidik TK TAAM Adinda Kepatihan Menganti Gresik

a. Perlu adanya pengembangan dan peningkatan kreativitas dan inovasi pendidik sebagai upaya penerapan strategi pengembangan PAI pada anak usia dini pada anak usia dini. 
b. Perlu adanya interaksi yang sesuai dan sinergis dalam menyampaikan kegiatan penerapan strategi pengembangan PAI pada anak usia dini.

3. Orang Tua/Wali

a. Selalu mendukung upaya sekolah dalam membimbing dan mengarahkan peserta didik terutama tentang kegiatan penerapan strategi pengembangan PAI pada anak usia dini.

b. Perlu adanya sinergitas antara orang tua dan sekolah dalam kegiatan penerapan strategi pengembangan PAI pada anak usia dini baik di sekolah maupun di rumah.

\section{DAFTAR PUSTAKA}

Abdullah Abdurrahman Saleh, Teori-teori Pendidikan berdasarkan AlQur'an, Jakarta: Rhineka Cipta, 2005

Ahmadi, dkk., Strategi Pembelajaran Sekolah Terpadu (pengaruhnya terhadap konsep, mekanisme dan proses pembelajaran sekolah swasta dan negeri), Jakarta : Prestasi Pustaka Publisher, 2011.

Ali Muhammad Daud, Pendidikan Agama Islam, Jaklarta : Raja Grafindo Persada, 2008.

Arifin, H. M. , Kapita Selekta Pendidikan (Islam dan Umum), Jakarta : Bumi Aksara, 2000.

Arsyad Azhar, Media Pembelajaran, Jakarta: Rajawali Pers, 2003.

Asy’ari, Pendidikan Islam, Jakarta : Rubbani Press, 2011.

Creswell J.W., Research Design: Pendekatan Kualitatif, Kuantitatif, dan Mixed Methodes Yogjakarta: PT Pustaka Pelajar, 2010.

Departemen Pendidikan dan Kebudayaan, Kamus Besar Bahasa Indonesia, Jakarta: Balai Pustaka. 2005.

Dimyati dan Mudjiono, Belajar dan Pembelajaran, Jakarta: Rineka Cipta, 2006.

D. Ahmad Marimba, Pengantar Filsafat Pendidikan, Bandung : AlMa'arif, 1989. 
F. Du Bois Nelson, Educational Psychology and Instructional Decision, Homewood : Illionis the Dorsey Press, 1979.

Lexy. J.Moleong, Metodologi Penelitian Kualitatif, (bandung:PT Remaja Rosdakarya, 2013.

Muhaimin, Nuansa Baru Pendidikan Islam (Mengurai Benang Kusut Pendidikan), Jakarta : PT. Raja Grafindo Persada, 2006.

----------, Rekonstruksi Pendidikan Islam (Dari Paradigma Pengembangan, Manajemen Kelembagaan, Kurikulum Hingga Strategi Pembelajaran), Jakarta : PT. Raja Grafindo Persada., 2009.

Mujib Abdul dan Yusuf Mudzakirn, Ilmu Pendidikan Islam, Jakarta : Kencana, 2008. Mukminan, Desain Pembelajaran, Yogyakarta: Program Pascasarjana Universitas Negeri Yogyakarta, 2004.

Nafis Ahmad H. Sukron, Manajemen Pendidikan, Yogyakarta :Laksang PRESSindo, 2011.

Nahlawi, An-, Abdurrahman, Ushulu al-Tarbiyah al-slamiyah, (Beirut : Dar al-Fikr, 1999.

Nata Abuddin, Perspektif Islam tentang Strategi Pembelajaran, Jakarta : Kencana Prenada Media group, 2009.

Nizar Syamsul dan Zainal Abidin Hasibuan, Hadist Tarbawi : Membangun Kerangka Pendidikan Ideal Perspektif Rosululloh, Jakarta: Kalam Mulia, 2011.

Noorlaila Iva, Petunjuk Teknis Pengembangan Silabus Mata Pelajaran Pendidikan Agama Islam, Jakarta : BSNP, 2006.

Pupuh Faturrohman dan Sutikno M. Sobry, Strategi Belajar Mengajar Melalui Penanaman Konsep Umum dan Konsep Islam, Bandung: PT Refika Aditama., 2014.

Republik Indonesia, Undang-undang Tentang Sistem Pendidikan Nasional Nomor 20 Tahun 2003, Jakarta: Sinar Grafika, 2006

Riyanto Yatim, Paradigma Baru Pembelajaran (Sebagai Referensi Bagi Pendidik dalam Implementasi Pembelajaran yang Efektif dan Berkualitas), Jakarta : Kencana Prenada Media Group, 2012. 
Rusman, Model-Model Pembelajaran, Mengembangkan Profesionalisme Guru, Jakarta: Rajawali Pers, 2012.

Rusman dkk., Pembelajaran Berbasis Tehnologi Informasi dan Komunikasi, Membangun Profesionalitas Guru, Jakarta: Rajawali Pers, 2011.

Siregar Eveline dan Nara, Hartini, Teori Belajar dan Pembelajaran, Cet. Ke-1, Bogor : Ghalia Indonesia, 2010.

Salma Dewi \& Eveline Siregar, Mozaik Teknologi Pendidikan, Jakarta: Prenada Media bekerjasama dengan Universitas Negeri Jakarta, 2004.

Suparno Paul dkk, Reformasi Pendidikan Sebuah Rekomendasi, Yogyakarta: Kanisius, 2002.

Suwaib Muhammad, Mendidik Anak Bersama Nabi (Panduan Lengkap Pendidikan Anak Disertai dengan Teladan Kehidupan Para salaf), terj. Salafudin Abu Sayyid, Surakarta : Pustaka Arafah, 2007.

Tafsir Ahmad, Filsafat Pendidikan Islam, Bandung : PT. Remaja Rosdakarya, 2008.

Tanzeh Ahmad, Metode Penelitian Praktis, Yogyakarta:Teras, 2009.

Ulwan Abdullah Nashih, Pendidikan Anak dalam Islam, Jakarta : Pustaka Amani, 2007.

Zuhairini dkk, Metodik Khusus Pendidikan Agama Dilengkapi dengan System Modul dan Permainan Simulasi, Surabaya : Usaha Nasional, 1983.

Wikipedia. (2007). Early Chilhood Education. Diakses dari http://en.wikipedia.org/wiki/early_chilhood_education. Pada tanggal 2 September 2014 , jam 11.11 WIB. 